\title{
126. Histochemical Localization of Prostaglandin Synthetase in the Rat Endometrium with Reference to Decidual Cell Reaction
}

\author{
By Yasuhiko OHTA \\ Department of Biology, School of General Education, \\ Tottori University, Koyama, Tottori 680 \\ (Communicated by Kiyoshi TakeWAKI, M. J. A., Dec. 12, 1985)
}

In some laboratory rodents, decidual cell reaction (DCR) can be induced by artificial stimuli applied to the endometrium appropriately sensitized by ovarian hormones. ${ }^{1)}$ Several lines of evidence have suggested involvement of prostaglandins (PGs) in DCR.2)-4) Although synthesis of PGs and its hormonal regulation in the endometrium have been studied biochemically at some length in the guinea pig and rat showing normal estrous cycles, ${ }^{5)-\tau}$ ) the possible role of ovarian steroids in the regulation of endometrial PG synthesis during DCR has not yet been duly studied. Since a histochemical method for demonstrating the cyclooxygenase activity involved in PG endoperoxide formation has already been developed by Janszen and Nugteren, ${ }^{8)}$ an analysis of histochemical localization of the PG synthetase was conducted in hormonally sensitized rat endometrium.

Materials and methods. Adult female rats (60 to 90 days of age) of the $\mathrm{T}$ strain used in these experiments were maintained in a temperature- and lightcontrolled room. In experiment 1 , three groups of ovariectomized rats ( $\mathrm{OX}$ rats) were given 3 daily injections of $0,0.3$ or $3 \mathrm{mg}$ progesterone (P) in $0.1 \mathrm{ml}$ sesame oil, respectively, commencing on the day after ovariectomy (12 rats/group). On the last day of the $\mathrm{P}$ injection period, each group was subdivided into 4 subgroups of 3 rats and given a single injection of $0,0.1,10$ and $100 \mu \mathrm{g}$ estradiol-17 $\beta\left(\mathrm{E}_{2}\right)$ in $0.05 \mathrm{ml}$ oil, respectively. All the rats were sacrificed $16 \mathrm{hr}$ after the $\mathrm{E}_{2}$ injection. The uteri removed immediately were frozen in liquid $\mathrm{N}_{2}$ and stored at $-80^{\circ} \mathrm{C}$ until use. Frozen sections cut with a cryostat-microtome at $10-15 \mu \mathrm{m}$ were incubated with $0.5 \mathrm{mg}$ arachidonic acid, $2 \mathrm{mg} 3,3^{\prime}$-diaminobenzidine tetrahydrochloride (DAB) and $0.65 \mathrm{mg} \mathrm{KCN}$, in $10 \mathrm{ml} 0.2 \mathrm{M}$ tris- $\mathrm{HCl}$ buffer ( $\mathrm{pH} \mathrm{8.0}$ ) for $3 \mathrm{hr}$ at $35^{\circ} \mathrm{C} .^{8)}$ Control sections were incubated similarly but without the fatty acid or after addition of $0.1 \mathrm{mg}$ indomethacin.9) The sections were rinsed with D.W. and embedded in glycerine jelly.

In experiment 2 , two groups of OX rats (40/group) were given 3 daily injections of 0.3 and $3 \mathrm{mg} \mathrm{P}$, respectively, from the day after ovariectomy, which were followed by 4 daily injections of $3 \mathrm{mg} \mathrm{P}$ in both 2 groups (designated 0.3-3 mg $\mathrm{P}$ group and 3-3 $\mathrm{mg} \mathrm{P}$ group, respectively). Daily doses of $\mathrm{P}$ were dissolved in $0.1 \mathrm{ml}$ sesame oil. On the $3 \mathrm{rd}$ day of the $\mathrm{P}$ injection period, each group was subdivided into 4 subgroups and given a single injection of $0,0.1$, 10 or $100 \mu \mathrm{g} \mathrm{E}_{2}$, respectively, in $0.05 \mathrm{ml}$ oil (subgroups $1-4$ of $0.3-3 \mathrm{mg} \mathrm{P}$ group and subgroups $5-8$ of $3-3 \mathrm{mg} P$ group). Sixteen $\mathrm{hr}$ after the $\mathrm{E}_{2}$ injection, the right uterine horn of one half of the rats from each subgroup $(n=5)$ was subjected to endometrial traumatization and the other half to intrauterine oilinstillation as deciduogenic stimuli. ${ }^{10)}$ On the day following the last $\mathrm{P}$ injection, 
the animals were sacrificed. The weights of the stimulated horns bearing deciduomata were used to estimate the size of DCR. Data were analyzed by Student's $t$ test and Fisher's exact probability test.

Results. 1) Histochemical localization of PG synthetase. In OX rats given no hormone treatment, incubation of uterine sections with arachidonic acid and $\mathrm{DAB}$ never produced a positive staining reaction in uterine tissues. A 3-day treatment with $\mathrm{P}$ alone following ovariectomy resulted in a positive reaction in the endometrium (Fig. 1), whereas a single injection of $\mathrm{E}_{2}$ alone given 3 days after ovariectomy produced hardly any staining in the tissue, regardless of doses of $\mathrm{E}_{2}$ (Fig. 3). The staining reaction in the $\mathrm{OX}$ rats treated with $\mathrm{P}$ alone was restricted to the luminal and glandular epithelial cells in the endometrium. The brown coloration was visible throughout the cell, except for the nucleus. In the OX rats treated with $0.3 \mathrm{mg} \mathrm{P}$, the reaction in the epithelial cells was much weaker than in those given $3 \mathrm{mg}$ (Fig. 2). A single injection of $\mathrm{E}_{2}$ given on
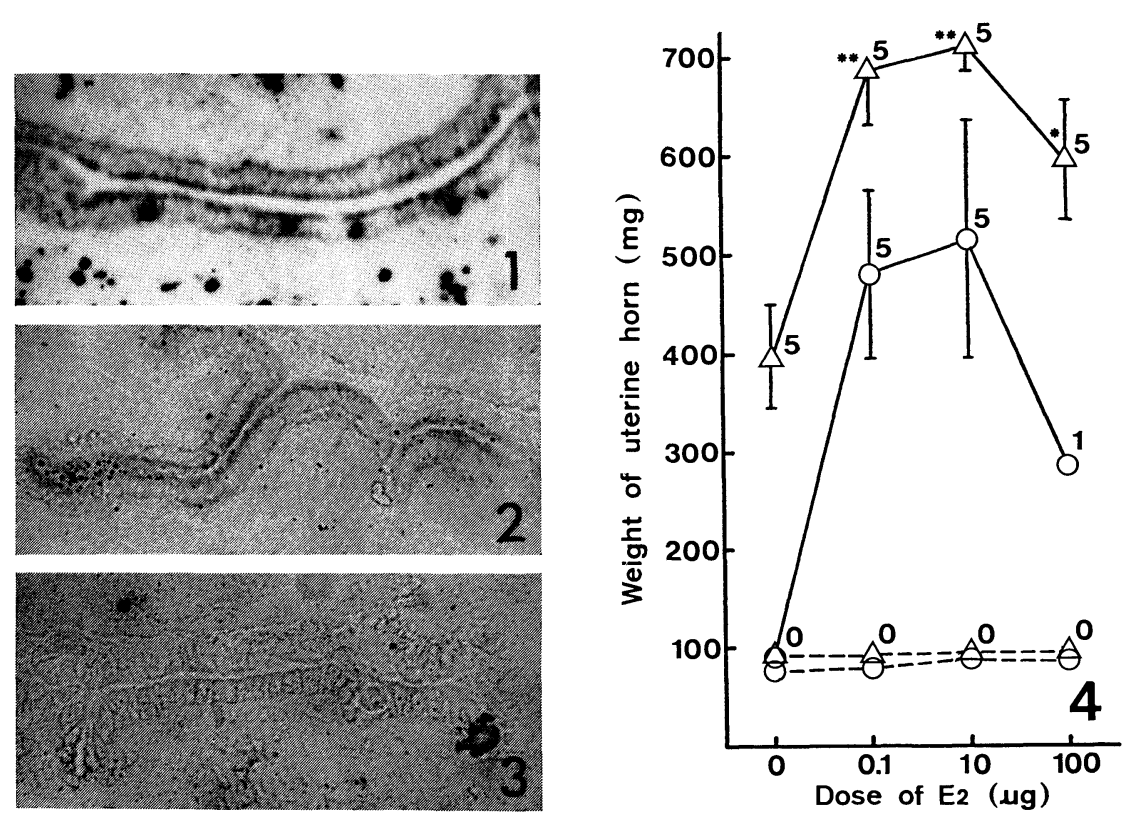

Figs. 1-3. Endometrial sections after incubation with arachidonic acid and DAB. $\times 110$. 1: Uterus from OX rat given 3 daily injections of $3 \mathrm{mg} \mathrm{P}$, showing enzyme activity in luminal epithelium. 2: Uterus from OX rat given 3 daily injections of $0.3 \mathrm{mg} \mathrm{P}$ plus $0.1 \mu \mathrm{g} \mathrm{E}_{2}$. Low enzyme activity in epithelium. 3: Uterus from OX rat given a single injection of $10 \mu \mathrm{g} \mathrm{E}_{2}$. Hardly any reaction in epithelium.

Fig. 4. Effects of 2 types of $P$ injections ( $3 \mathrm{mg}$ for 3 days, $3 \mathrm{mg}$ for 4 days, solid line; $0.3 \mathrm{mg}$ for 3 days, $3 \mathrm{mg}$ for 4 days, broken line) combined with different doses of $E_{2}$ on the induction of DCR following trauma $(\triangle)$ or oil instillation $(O)$. Each point represents the number of rats showing positive response. Significance of differences from a group given no $\mathrm{E}_{2}$ injection. $* \mathrm{P}<0.05$. $* * \mathrm{P}<0.01$.

the 3rd day of the $\mathrm{P}$ injection period failed to exert any effect on P-induced $\mathrm{PG}$ synthetase activity in the endometrium. Control sections incubated in the medium without substrate or with indomethacin showed hardly any staining in the uterine tissues, except for leucocytes which reacted nonspecifically. 
2) Decidual cell reaction $(D C R)$. As shown in Fig. 4, the $\mathrm{OX}$ rats given 7 daily injections of $3 \mathrm{mg} \mathrm{P}$ and a single injection of $0,0.1,10$ or $100 \mu \mathrm{g} \mathrm{E}_{2}$ on the 3rd day of the injection period (3-3 mg P rats) invariably formed deciduomata in response to uterine traumatization, regardless of doses of $E_{2}$, although the response was smallest in size in those given no $\mathrm{E}_{2}$. By contrast, the uterine responses in similar rats to oil instillation were different in incidence and size, according to doses of $\mathrm{E}_{2}$, the highest DCR being induced by $\mathrm{E}_{2}$ at doses 0.1 and $10 \mu \mathrm{g}$. If the dose was increased to $100 \mu \mathrm{g}$, the DCR was inhibited, its incidence being reduced to $20 \%$ (vs those given 0.1 or $10 \mu \mathrm{g}, \mathrm{P}=0.023$ ). The oil instillation failed to induce any significant response in those given injections of $\mathrm{P}$ alone. In 0.3-3 mg P groups, the uteri responded neither to trauma nor to oil-instillation, whether $\mathrm{E}_{2}$ was given or not.

Discussion. Incubation with arachidonic acid (the precursor fatty acid of PGE-2 and PGF-2 $\alpha$ ) and DAB resulted in staining reaction in luminal and glandular epithelial cells of the endometrium, only in the OX rats treated with $P$. The $O X$ rats given no $P$ failed to exhibit any positive reaction. The intensity of the reaction was dependent upon the dose of $P$. In P-treated rats, estrogen acted neither synergistically nor antagonistically in the reaction. These findings appear to indicate that PGs are produced only by epithelial cells in the endometrium and progesterone may be involved in the endometrial PG synthesis by regulating cyclooxygenase activity, whereas estrogen seems to have little effect on the PG synthetase activity. This conclusion is not in agreement with the results of biochemical studies by Naylor and Poyser ${ }^{5)}$ and Ham et al. ${ }^{(5)}$ that estrogen, but not progestin, was capable of altering uterine PG synthesis by modulating the PG synthetase activity.

The uterine DCR seems to be in close relation to the PG synthetase activity in the endometrium at the time of exposure to the deciduogenic stimulus. When the enzyme activity in the endometrium was low following injections of low doses of P, DCR failed to occur, regardless of doses of estrogen. In the OX rats treated with $3 \mathrm{mg} \mathrm{P}$, however, the response to oil instillation was not closely related to the enzyme activity in the endometrium. It has already been pointed out that a single injection of estrogen mimicking a "nidatory surge estrogen", in association with $\mathrm{P}$ injection, is essential for induction of DCR by oil-instillation, while the nidatory surge estrogen is not required for the induction of the response by endometrial traumatization. ${ }^{11.12)}$ In the present study, the uteri failed to respond to oil instillation in the $\mathrm{OX}$ rats given a 7 -day $\mathrm{P}$ treatment without a single injection of $\mathrm{E}_{2}$ on the third day. However, an optimum dose range of estrogen is present as has been reported by Finn, ${ }^{11)}$ DCR being inhibited by overdose estrogen.

Estrogen injection was incapable of altering the progestin-induced enzyme activity in the endometrium (vide supra). Therefore, the enhanced PG synthetase activity in the endometrium does not appear to co-operate with estrogen in the induction of DCR. Nevertheless, since Downing and Poyser ${ }^{13}$ ) have demonstrated that estrogen initiates the PG synthesis by activating phospholipase A-2 responsible for releasing arachidonic acid from phospholipids in the progesteroneprimed guinea pig uterus, the possibility cannot be overlooked that the nidatory surge estrogen is involved in the production of PGs by the uterus during decidualization. 
Acknowledgements. The author thanks Emeritus Professor K. Takewaki of the University of Tokyo, M. J. A., for his critical reading of the manuscript. This work was supported by a research grant from the Itoh Science Foundation.

\section{References}

1) Finn, C. A., and Porter, D. G.: Reproductive Biology Handbooks, The Uterus. vol. 1. Publishing Science Groups, London, pp. 74-93 (1975).

2) Lau, I. F., Saksena, S. K., and Chang, M. C.: Prostaglandiins, 4, 795-803 (1973).

3) Rankin, J. C. et al.: Biol. Reprod., 20, 399-404 (1979).

4) Kennedy, T. G.: ibid., 23, 519-525 (1980).

5) Naylor, B., and Poyser, N. L.: Br. J. Pharmac., 55, 229-232 (1975).

6) Ham, E. A. et al.: Proc. Nat. Acad. Sci., 72, 1420-1424 (1975).

7) Brown, C. G., and Poyser, N. L.: J. Reprod. Fert., 73, 391-399 (1985).

8) Janszen, F. H. A., and Nugteren, D. H.: Histochemie, 27, 159-164 (1971).

9) Vane, J. R.: Nat. New Biol., 231, 232-235 (1971).

10) Ohta, Y.: Biol. Reprod., 27, 308-311 (1982).

11) Finn, C. A.: J. Endocr., 36, 239-248 (1966).

12) Sananes, N., Baulieu, E. E., and Le Goascognae, C.: ibid., 36, 25-33 (1981).

13) Downing, I., and Poyser, N. L.: Prostaglandins, Leuk. and Med., 12, 107-117 (1983). 